\title{
Design of ACI-type punching shear reinforcement to Eurocode 2
}

\author{
R. L. Vollum*, T. Abdel-Fattah†, M. Eder* and A. Y. Elghazouli*
}

Imperial College London; Housing and Building Research Centre, Cairo

This paper describes a series of tests that were carried out at Imperial College London to determine the efficiency of stirrups when used as ACI-type punching shear reinforcement at internal columns. Six 3 m square slabs were tested with various arrangements of punching shear reinforcement. The variables considered in the tests included the area of shear reinforcement and the extension of the stirrups from the column face. The measured shear strengths were compared with the shear strengths predicted with Eurocode 2 and ACI 318. The design method in Eurocode 2 is shown to be overly conservative for ACI-type punching shear reinforcement and a modification is proposed. The paper describes a series of three-dimensional non-linear finite-element analyses which were carried out to gain a better appreciation of the parameters influencing the efficiency of ACI-type shear reinforcement and to assist in the validation of the proposed design method. The non-linear finite-element analysis is shown to give good predictions of the measured shear strengths of the tested slabs.

\begin{tabular}{|c|c|}
\hline Nota & \\
\hline$A_{\mathrm{sw}}$ & area of shear reinforcement in each perimeter \\
\hline$c$ & column width \\
\hline$d$ & slab effective depth \\
\hline$f_{\mathrm{ck}}$ & concrete cylinder strength \\
\hline$f_{\text {ydef }}$ & $\begin{array}{l}\text { effective design strength for punching shear } \\
\text { reinforcement }\end{array}$ \\
\hline$U_{1}$ & inner control perimeter \\
\hline$U_{\text {out }}$ & outer control perimeter \\
\hline$U_{\text {outeff }}$ & EC2 effective outer control perimeter \\
\hline$V_{\mathrm{cEC} 2}$ & $\begin{array}{l}\text { EC2 shear strength without shear } \\
\text { reinforcement (subscript d refers to design } \\
\text { shear strength with } \gamma_{c}=1 \cdot 5 \text { ) }\end{array}$ \\
\hline$V_{\mathrm{Ed}}$ & design shear force \\
\hline$V_{\mathrm{EC} 2}$ & $\begin{array}{l}\text { EC2 shear strength (subscript d refers to } \\
\text { design shear strength with } \gamma_{c}=1 \cdot 5 \text { ) }\end{array}$ \\
\hline$V_{\text {in }}$ & $\begin{array}{l}\text { calculated shear strength within shear } \\
\text { reinforcement }\end{array}$ \\
\hline$V_{\text {out }}$ & $\begin{array}{l}\text { calculated shear strength outside shear } \\
\text { reinforcement }\end{array}$ \\
\hline$V_{\mathrm{Rd}}$ & design shear resistance \\
\hline$V_{\text {test }}$ & measured shear strength \\
\hline
\end{tabular}

* Imperial College London, UK

$\uparrow$ Housing and Building Research Centre, Cairo, Egypt

(MACR 900044) Paper received 16 March 2009; accepted 15 June 2009

$\begin{array}{ll}v & \text { shear stress (subscripts as for } V \text { which denotes } \\ \text { shear force) } & \text { width of shear reinforcement in each arm of } \\ & \text { cruciform } \\ & \text { distance to outer stirrup from column face }\end{array}$

\section{Introduction}

Figure 1 shows typical examples of ACI (ACI, 2005), radial and UK-type punching shear reinforcement in plan. The first shear stud or stirrup is typically placed within $0 \cdot 5 d$, where $d$ is the effective depth, from the column face. Process research at Cardington (Goodchild, 2000) found ACI-type punching shear reinforcement to be very economic. The main obstacle to the use of ACI-type shear reinforcement in the UK is that its design is not covered by BS 8110 (BSI, 2007), which assumes shear reinforcement to be evenly distributed in rectangular perimeters centred on the column as shown in Figure 1(c). Eurocode 2 (BSI, 2004) can be used to design ACI-type shear reinforcement but the maximum possible shear strength is severely limited owing to the restriction placed on the maximum possible length of the outer shear perimeter. A literature review revealed a remarkable lack of data from tests on slabs with stirrups arranged in the ACI punching shear configuration with the authors only able to identify data from tests carried out by Hawkins et al. (1989) on eccentrically loaded internal column speci- 


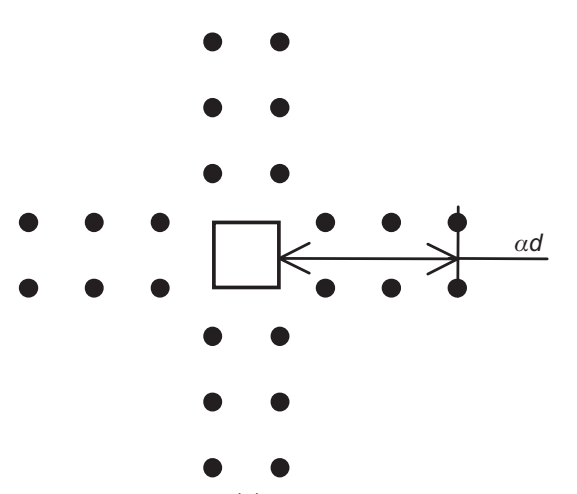

(a)
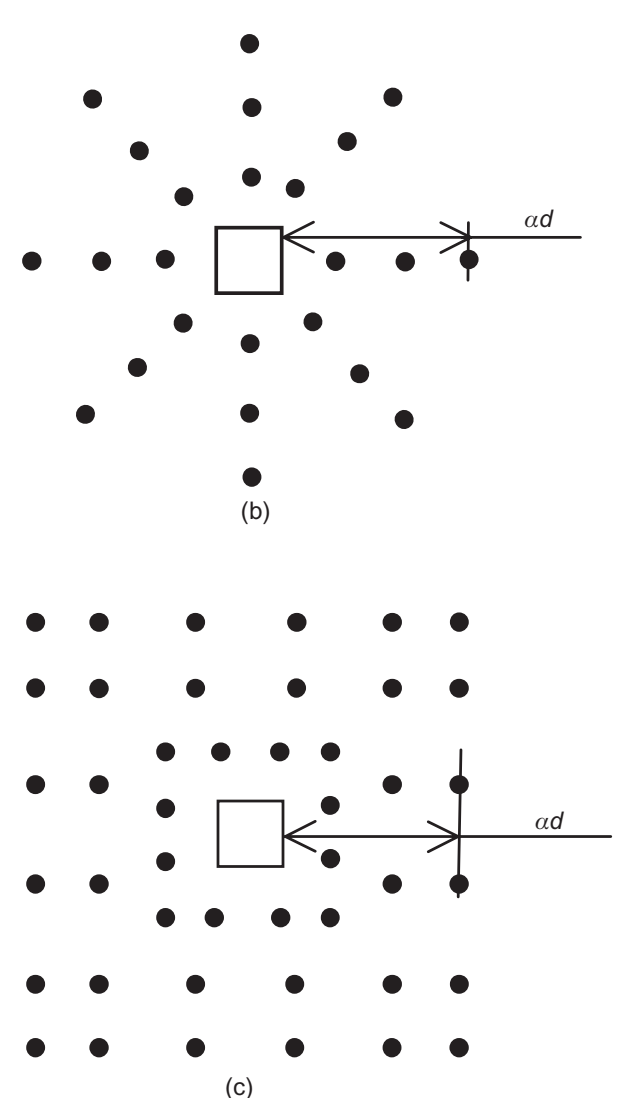

Figure 1. Arrangement of punching shear reinforcement: (a) ACI-type; (b) radial; (c) UK type

mens. These data were of limited use in assessing punching strength as the tests were typically halted prior to punching failure owing to excessive deflection.

\section{Experimental programme}

This paper describes a series of six punching shear tests that were carried out at Imperial College London to determine the effectiveness of ACI-type shear stirrups. The test specimens measured $3 \mathrm{~m}$ square by $220 \mathrm{~mm}$ thick and were centrally loaded through a $270 \mathrm{~mm}$ square steel plate as shown in Figure 2. Details of the specimens and corresponding concrete strengths are summarised in Table 1. Slab 1 was a control specimen, which was not reinforced in shear. The concrete target cube strength was $30 \mathrm{MPa}$ and the maximum aggregate size was $20 \mathrm{~mm}$. Deformed bars of $16 \mathrm{~mm}$ diameter were used for the tensile flexural reinforcement in the slabs and $10 \mathrm{~mm}$ diameter deformed bars were used as compression reinforcement. The tensile reinforcement was uniformly spaced across the width of the slabs with a spacing of $90 \mathrm{~mm}$ in slabs 1 to 5 and $180 \mathrm{~mm}$ in slab 6 . The bars were anchored with Ushaped hooks at each end. The spacing of the $10 \mathrm{~mm}$ diameter compression reinforcement was $180 \mathrm{~mm}$ in all the slabs. The yield strengths of the reinforcement were $485 \mathrm{MPa}, 560 \mathrm{MPa}$ and $567 \mathrm{MPa}$ for the $8 \mathrm{~mm}, 10 \mathrm{~mm}$ and $16 \mathrm{~mm}$ diameter bars respectively. Table 1 gives details of the stirrups provided in each specimen. Bars of $10 \mathrm{~mm}$ diameter located in the outer layer of flexural reinforcement were provided in the corners of the stirrups for anchorage. The stirrups were $150 \mathrm{~mm}$ wide and were spaced at $90 \mathrm{~mm}$ centres in all the tests with the first stirrup placed $90 \mathrm{~mm}$ outside the face of the loaded area. The lap in the stirrup was placed at the bottom of the slab. It is convenient to express the distance from the face of the loaded area to the outer stirrups as $\alpha d$ (see Figure 1) where $d$ is the effective depth of the slab. The tests were designed to investigate the effects on shear strength and ductility of varying: (a) the stirrup area, (b) the stirrup projection $\alpha d$ (see Table 1) and (c) the flexural reinforcement ratio $\rho=100 A_{\mathrm{s}} / b d$. Figure 2 shows details of the test rig used in this study.

The specimens were loaded through the central jack and restrained vertically with 16 ties positioned around the perimeter of the slab as shown in Figure 2. Deflections were measured in the top surface of the slab with an orthogonal grid of 14 linear variable differential transducers (LVDTs) spaced at $750 \mathrm{~mm}$ centres with the central transducer placed at the centre of the slab. The failure loads of the specimens are listed in Table 1, which shows that the shear reinforcement increased the punching strength. Figure 3 shows load-deflection curves for all the slabs. The deflections were similar in all the slabs up to their peak load with the exception of slab 6, which had 50\% less flexural reinforcement than the other slabs. The ductility of the punching shear failure but not the failure load increased when the distance to the last stirrup $\alpha d$ (see Figure 1) was increased from $3 d$ to $5 d$. This can be seen by comparing the loaddeflection curves for tests 2 and 5 , in which $\alpha d$ was $5 d$, with those for tests 3 and 4 in which $\alpha d$ was $3 d$. The increased ductility of slab 5 compared with slab 2 appears to be attributable to the $8 \mathrm{~mm}$ diameter stirrups in slab 5 being better anchored than the $10 \mathrm{~mm}$ stirrups in slab 2. Slab 6, which was designed to fail in flexure, failed with significant ductility in combined shear and flexure at $740 \mathrm{kN}$, which is close to the flexural capacity of $752 \mathrm{kN}$ calculated with yield line analysis.

Magazine of Concrete Research, 2010, 62, No. 1 


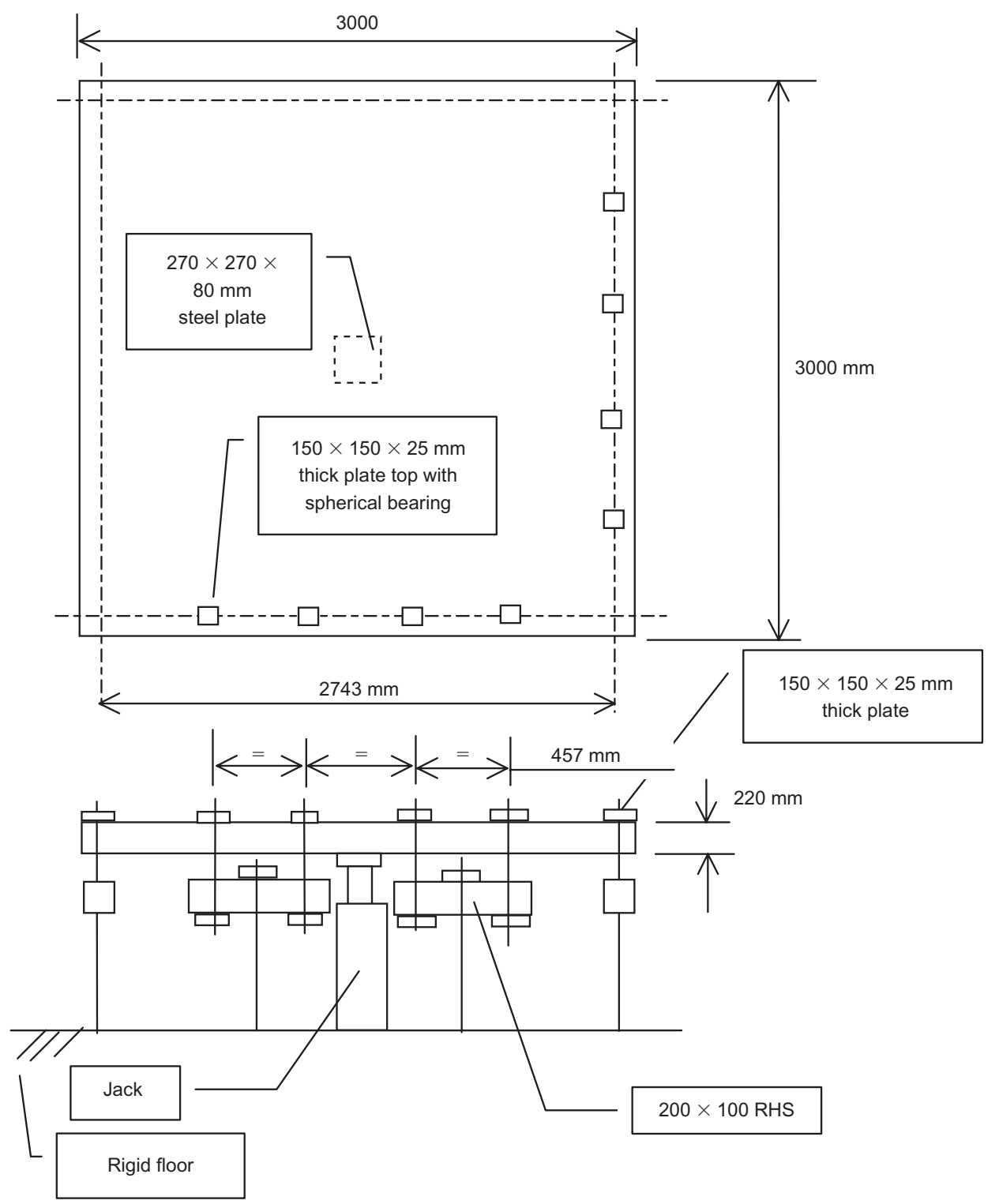

Figure 2. Test rig

Table 1. Details of test specimens

\begin{tabular}{|c|c|c|c|c|c|c|c|c|c|}
\hline Test & $f_{\mathrm{c}}: \mathrm{MPa}$ & $d_{x}: \mathrm{mm}$ & $d_{y}: \mathrm{mm}$ & $\rho: \%$ & Description of shear reinforcement & $V_{\text {utest }}: \mathrm{kN}$ & $V_{\text {uNLFEA }}: \mathrm{kN}$ & $\begin{array}{l}(\%) \text { error } \\
\text { NLFEA* }\end{array}$ & $P_{\text {flex }}: \mathrm{kN}$ \\
\hline 1 & $24 \cdot 0$ & 166 & 182 & $1 \cdot 28$ & None & 614 & 644 & $4 \cdot 89$ & 1225 \\
\hline 2 & $24 \cdot 0$ & 166 & 182 & $1 \cdot 28$ & 10 mm stirrups @90mm, $\alpha=5$ & 843 & 876 & $3 \cdot 91$ & 1225 \\
\hline 3 & $27 \cdot 2$ & 166 & 182 & $1 \cdot 28$ & 10 mm stirrups@90mm, $\alpha=3$ & 903 & 884 & $-2 \cdot 43$ & 1252 \\
\hline 4 & $27 \cdot 2$ & 166 & 182 & $1 \cdot 28$ & 8 mm stirrups @ 90 mm, $\alpha=3$ & 906 & 888 & -1.99 & 1252 \\
\hline 5 & $23 \cdot 2$ & 166 & 182 & $1 \cdot 28$ & $8 \mathrm{~mm}$ stirrups in pairs @ $90 \mathrm{~mm}, \alpha=5$ & 872 & 880 & $0 \cdot 92$ & 1217 \\
\hline 6 & $23 \cdot 2$ & 166 & 182 & 0.64 & $8 \mathrm{~mm}$ stirrups in pairs $@ 90 \mathrm{~mm}, \alpha=5$ & 740 & 748 & $1 \cdot 08$ & 752 \\
\hline
\end{tabular}

* NLFEA, non-linear finite-element analysis

\section{Crack pattern}

Radial cracks first formed at around $300 \mathrm{kN}$ in all the tests and spread from the centre of the slab to its perimeter as the test progressed. Circumferential cracks formed subsequently to the radial cracks and were typically contained within a radius of around $450 \mathrm{~mm}$. The punching shear failures were characterised by the penetration of the bearing plate into the slab. The punching failure was not visible in the top surface of the slab except in slab 6 where the failure surface was semicircular with radius around $900 \mathrm{~mm}$ (i.e. within the shear reinforcement) and centred on the loading platen. The slabs were sawn in half for disposal after the tests. Figure 4 shows the crack pattern along the 


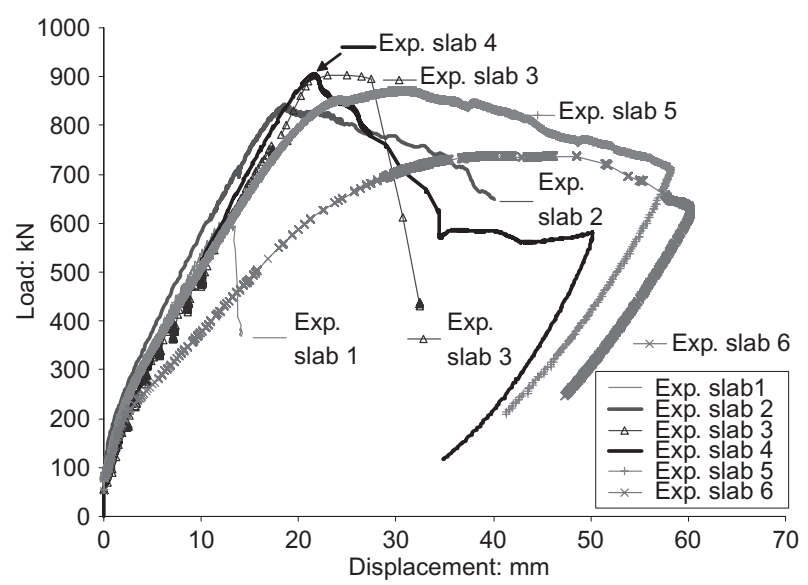

Figure 3. Comparison of load-deflection curves for slabs 1 to 6

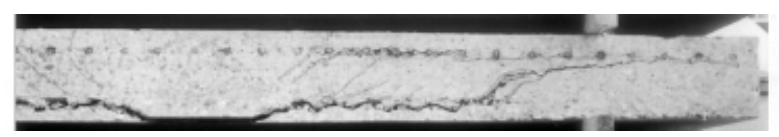

(a)

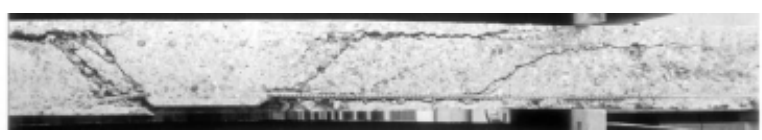

(b)

Figure 4. Crack patterns for: (a) slab $3(\alpha=3)$; (b) slab 4 $(\alpha=3)$

sawn edges of slabs 3 and 4 . Figure 4 indicates that the top and bottom flexural reinforcement de-bonded along the length of the shear reinforcement at failure and that shear cracks formed outside the last stirrup. Examination of the cracks in sawn edges suggested that the stirrups only yielded in slab 4 in which $8 \mathrm{~mm}$ diameter stirrups were used at $90 \mathrm{~mm}$ spacing. The shear failure in slab 4 appeared to occur both within the shear reinforcement adjacent to the loaded area and outside the shear reinforcement. Crack widths up to $2.4 \mathrm{~mm}$ were measured in slab 6 over the loading platen, indicating extensive yielding of the flexural reinforcement, which is consistent with the large deflection at failure.

\section{Comparison with codes of practice (EC2-ACI 318)}

The shear strengths of the tested specimens were compared with the strengths given by the design methods in Eurocode 2 and ACI 318, which are summarised in Tables 2(a) and 2(b) respectively. Eurocode 2 uses material factors of safety of 1.5 for concrete and 1.15 for reinforcement whereas ACI 318 uses a capacity reduction factor of 0.75 for shear. Both codes require the shear stress to be checked at a basic control perimeter $U_{1}$ along which the design shear stress $v_{\mathrm{Ed}}$ which is given by

$$
v_{\mathrm{Ed}}=\frac{V_{\mathrm{Ed}}}{U_{1} d}
$$

where $V_{\mathrm{Ed}}$ is the effective design shear force and $d$ is the mean effective depth to the flexural reinforcement. ACI 318 takes the basic control perimeter as $U_{1}=4(c+d)$ for a square column with sides of length $c$ where $d$ is the effective depth to the flexural reinforcement. Eurocode 2 takes the corresponding perimeter as $U_{1}=4(c+\pi d)$.

Shear reinforcement is required if the design shear stress on the basic control perimeter $v_{\mathrm{Ed}}$ (see Equation 1) is greater than the design shear strength without shear reinforcement, $v_{\mathrm{R}, \mathrm{Cd}}$, which is defined in Tables 2(a) and 2(b) for Eurocode 2 and ACI 318 respectively. If required, shear reinforcement needs to be provided on successive perimeters around the column until the design shear stress is less than $v_{\mathrm{R}, \mathrm{Cd}}$ on the control perimeter outside the shear reinforcement shown in Figure 5(a) for ACI 318 and in Figure 5(b) for Eurocode 2 with ACI-type shear reinforcement. The effective outer perimeter is restricted to $U_{\text {outeff }} \leqslant 4 x+3 \pi d+$ $8 d$ for ACI-type shear reinforcement in Eurocode 2 where $x$ (see Figure 5(b)) is the width of shear reinforcement in each arm of the cruciform (i.e. the stirrup width in the current tests).

Eurocode 2 also limits the maximum shear stress in the slab at the column perimeter to $v_{\mathrm{R}, \max }$, which is defined as follows

$$
v_{\mathrm{R}, \max }=0.5 v f_{\mathrm{ck}} / \gamma_{\mathrm{c}}
$$

where

$$
v=0 \cdot 6\left(1-\frac{f_{\mathrm{ck}}}{250}\right) \text { in which } f_{\mathrm{ck}} \text { is in } \mathrm{MPa}
$$

The measured shear strengths are compared with the values given by Eurocode 2 and ACI 318 respectively in Table 3, which gives shear capacities for slabs 1 to 6 within and outside the shear reinforcement. In the case of Eurocode 2, shear strengths were calculated with the material factor of safety $\gamma_{c}$ for concrete equal to $1 \cdot 0$ and $1 \cdot 5$. Walraven (2001) discusses the rational behind the coefficient of $0 \cdot 18$ in the Eurocode 2 equation for $v_{\mathrm{c}}$ (see Equation T1 in Table 2(a)) in the background document for punching shear. It is shown that the shear strength calculated with $\gamma_{\mathrm{c}}=1.0$ is close to the mean strength of 112 specimens without shear reinforcement with depths ranging between $100 \mathrm{~mm}$ and $275 \mathrm{~mm}$. The capacity reduction factor, $\phi$, was taken as 1.0 in the ACI design equations. Table 1 gives the flexural capacities of the slabs which were calculated with yield line analysis as follows (Seible et al., 1980)

$$
P=m\left(\frac{8 L}{L-c}-1.373\right)
$$

where $m$ is the moment of resistance in $\mathrm{kNm} / \mathrm{m}, L$ is the slab span and $c$ is the column width.

The equation for shear strength in ACI 318 differs from that in Eurocode 2 in that (a) it does not relate the shear strength to the flexural reinforcement ratio and (b) the basic shear strength $v_{\mathrm{c}}$ is independent of the 
Table 2(a). Eurocode 2 design equations for punching shear

\begin{tabular}{|c|c|}
\hline Code & Design equations \\
\hline Eurocode 2 & $\begin{array}{l}v_{\mathrm{Rd}, \mathrm{C}}=0 \cdot 18 k\left(100 \rho_{\mathrm{l}} f_{\mathrm{c}}\right)^{1 / 3} / \gamma_{\mathrm{c}} \\
\text { where } \\
\gamma_{\mathrm{c}}=1 \cdot 5 \text { for design } \\
f_{\mathrm{ck}} \text { is in } \mathrm{MPa} \\
k=1+\sqrt{\frac{200}{d}} \leqslant 2 \cdot 0 d \text { in mm } \\
\rho_{\mathrm{l}}=\sqrt{\rho_{\mathrm{lx}} \rho_{\mathrm{l} y}} \leqslant 0 \cdot 02 \\
\rho_{\mathrm{lx}}, \rho_{1 y} \text { relate to the bonded tension steel in the } x \text { - and } y \text {-directions respectively. The values of } \rho_{\mathrm{lx}} \text { and } \rho_{1 y} \text { should } \\
\text { be calculated as mean values taking into account a slab width equal to the column width plus } 3 d \text { each side. } \\
v_{\mathrm{RdCS}}=0 \cdot 75 v_{\mathrm{RdC}}+1 \cdot 5\left(d / S_{\mathrm{r}}\right) A_{\mathrm{SW}} f_{\mathrm{YWdef}}\left(\frac{1}{u_{1} d}\right) \\
\text { where } \\
f_{\mathrm{YWd}, \mathrm{ef}} \text { is in MPa } \\
A_{\mathrm{SW}} \text { is the area of one perimeter of shear reinforcement around the column }\left[\mathrm{mm}^{2}\right] \\
S_{\mathrm{r}} \text { is the spacing of shear links in the radial direction }[\mathrm{mm}] S_{\mathrm{r}} \leqslant 0 \cdot 75 d \\
f_{\mathrm{YW}, \text { ef }} \text { is the effective strength of the punching shear reinforcement, according to } \\
f_{\mathrm{Ywd}, \text { ef }}=(250+0 \cdot 25 d) \leqslant f_{\mathrm{ywd}}=\frac{f_{\mathrm{yw}}}{\gamma_{\mathrm{s}}=1 \cdot 15} \quad \text { (MPa) }\end{array}$ \\
\hline
\end{tabular}

Table 2(b). ACI 318 design equations for punching shear

\begin{tabular}{l|l}
\hline Code & Design equations \\
\hline ACI 318 & $\begin{array}{l}v_{\mathrm{R}, \mathrm{C}} \text { shall be the smaller of (a), and (b) } \\
\text { (a) } v_{\mathrm{R}, \mathrm{C}}=0.083\left(\frac{40 d_{\mathrm{eff}}}{u_{1}}+2\right) \sqrt{f_{\mathrm{c}}} \\
\text { (b) } v_{\mathrm{R}, \mathrm{C}}=0.33 \sqrt{f_{\mathrm{c}}} \\
\text { where } \\
f_{\mathrm{c}} \text { is in MPa; } f_{\mathrm{c}}<70 \quad \mathrm{MPa} \\
v_{\mathrm{R}, \mathrm{CS}}=0 \cdot 167 \sqrt{f_{\mathrm{c}}}+\frac{d}{S_{\mathrm{r}}} A_{\mathrm{SW}} f_{\mathrm{Y}}\left(\frac{1}{u_{1} d}\right) \leqslant 0 \cdot 5 \sqrt{f_{\mathrm{c}}} \\
\text { where } \\
f_{\mathrm{c}} \text { and } f_{\mathrm{YW}, \text { ef }} \text { is in MPa } \\
A_{\mathrm{SW}} \text { is the area of one perimeter of shear reinforcement around the column }[\mathrm{mm}] \\
S_{\mathrm{r}} \leqslant 0 \cdot 5 d \\
\text { The shear stress on the outer perimeter is limited to } v_{\mathrm{R}, \mathrm{C}}=0 \cdot 167 \sqrt{f_{\mathrm{c}}}\end{array}$ \\
\hline
\end{tabular}

slab depth. Table 3 shows that Eurocode 2 accurately predicts the shear strength of slab 1 which had no shear reinforcement, unlike ACI 318 which underestimates the shear strength. Both Eurocode 2 and ACI 318 give similar basic shear strengths $v_{\mathrm{c}}$ for slab 6 , which had a lower reinforcement ratio of $0 \cdot 64 \%$. Table 3 shows that the shear strengths given by ACI 318 are controlled by the outer control perimeter when the stirrup projection $\alpha d=3 d$ and by the maximum allowable shear stress on the basic control perimeter $U_{1}$ when $\alpha d=5 d$. The shear strengths given by Eurocode 2 are controlled by the length of the outer shear perimeter $U_{\text {outeff for all the }}$ tested slabs with stirrups. ACI 318 gives significantly

Magazine of Concrete Research, 2010, 62, No. 1 greater design strengths for the tested slabs with stirrups and $\alpha d=5 d$ due to (a) the restriction on $U_{\text {outeff }}$ in Eurocode 2 and (b) the capacity reduction factor being 0.75 in ACI 318 compared with $2 / 3$ in Eurocode 2 for failure outside the shear reinforcement.

\section{Analysis of data from other tests}

Table 3 shows that Eurocode 2 underestimates the punching shear strength of the tested slabs with ACItype shear reinforcement when $\gamma_{c}=1.0$ as the length of the effective outer perimeter is underestimated. Data 


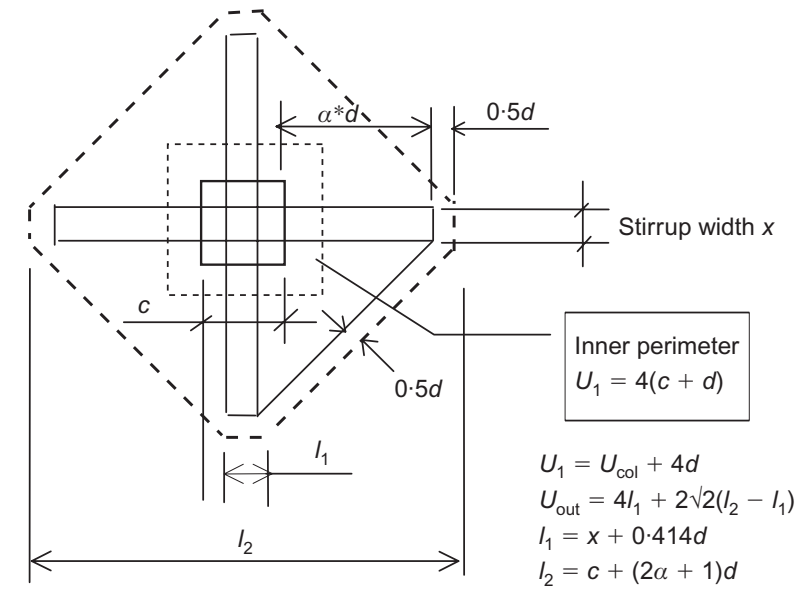

(a)

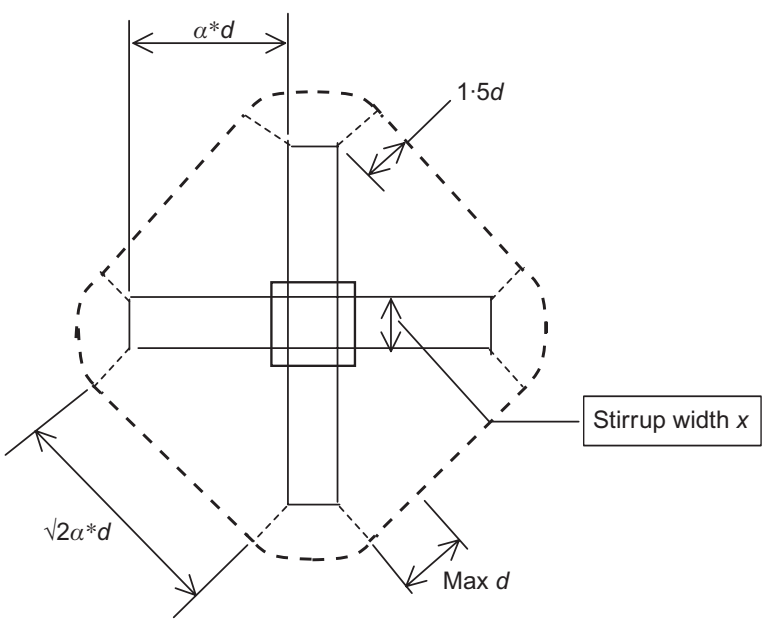

Maximum possible outer perimeter $U_{\text {out }}=4 x+3 \pi d+4 \sqrt{ } 2 \alpha^{*} d$ Eurocode 2 effective outer perimeter $U_{\text {out eff }} \leqslant 4 x+3 \pi d+8 d$

(b)

Figure 5 (a) ACI outer perimeter; (b) Eurocode 2 outer perimeter

from the tests of Chana and Desai (1992), Gomes and Regan (1999), Marzouk and Jiang (1997), Mokhtar et al. (1985), Regan and Samadian (2001) and Seible et al. (1980), were analysed alongside the authors' data to determine whether the restriction on $U_{\text {outeff }}$ is justified. The specimens of Seible et al. (1980), Marzouk and Jiang (1997) and Mokhtar et al. (1985) were reinforced with shear studs in the ACI configuration. The specimens of Gomes and Regan (1999) were reinforced with off-cuts from I sections which were arranged in the ACI pattern in tests 2 to 5 and radially in tests 6 to 11 . The width of each arm in the ACI cross (i.e. dimension $x$ in Figure 5(b)) was equal to $160 \mathrm{~mm}$ in the specimens of Gomes and Regan (1999) and the column width in the specimens of Seible et al. (1980), Marzouk and Jiang (1997) and Mokhtar et al. (1985). Chana and Desai's (1992) specimens were reinforced in accordance with traditional UK practice where stirrups are distributed on square perimeters around the column. All the series of tests examined except that of Seible et al. (1980) included control slabs without shear reinforcement. The shear strengths of the control specimens without stirrups are compared with the shear strengths given by Eurocode 2 in Table 4 . The test data were analysed to determine the influence of the shear reinforcement arrangement and type on the maximum possible increase in shear strength by plotting $V_{\text {test }} / V_{\mathrm{cEC} 2}$ with $\gamma_{\mathrm{c}}=1$ against $U_{\text {out }} / U_{1}$ where $U_{\text {out }}$ is the full outer perimeter (see Figure $5(\mathrm{~b})$ ), which was defined as follows

$$
U_{\text {out }}=3 \pi d+\Sigma s
$$

where $s$ is the circumferential spacing between the outer stirrups or studs. In the case of ACI-type shear reinforcement $\Sigma s$ was taken as $\Sigma s=4\left(\sqrt{ } 2 \alpha^{*} d+x\right)$ where $x$ (see Figure 5) is the stirrup width. In the case of Chana and Desai's (1992) specimens, $U_{\text {out }}$ was taken as

$$
U_{\text {out }}=2 \pi(\alpha+1 \cdot 5) d+4 c
$$

The results of the analysis are plotted in Figure 6(a), which suggests there is an upper limit to the shear strength of specimens reinforced with ACI-type shear reinforcement of $\sim 1 \cdot 3 v_{\mathrm{cEC} 2}\left(=2 v_{\mathrm{cEC} 2 \text { design }}\right)$. Where relevant to the discussion, the failure mode is noted as 'inside' or 'outside' the shear reinforcement in Figure 6 and subsequently. Figure 6(a) shows that the effective

\begin{tabular}{|c|c|c|c|c|c|c|c|c|c|c|}
\hline \multirow{3}{*}{$\begin{array}{l}\text { Method } \\
\\
\text { Slab }\end{array}$} & \multirow{2}{*}{\multicolumn{4}{|c|}{ ACI 318}} & \multicolumn{4}{|c|}{ Eurocode 2} & \multicolumn{2}{|c|}{ Proposed } \\
\hline & & & & & \multicolumn{2}{|c|}{$\gamma_{\mathrm{c}}=1$} & \multicolumn{2}{|c|}{$\gamma_{\mathrm{c}}=1.5$} & \multirow{2}{*}{$\begin{array}{c}v_{\mathrm{c}}=1 \\
V_{\text {out }} / V_{\text {test }}\end{array}$} & \multirow{2}{*}{$\begin{array}{l}v_{\mathrm{c}}=1.5 \\
V_{\text {out }} / V_{\text {test }}\end{array}$} \\
\hline & $V_{\text {in }} / V_{\text {test }}$ & $V_{\text {out }} / V_{\text {test }}$ & $V_{\max } * / V_{\text {test }}$ & $\begin{array}{c}0 \cdot 85^{\psi} \\
V_{\text {crit }} / V_{\text {test }}\end{array}$ & $V_{\text {in }} / V_{\text {test }}$ & $V_{\text {out }} / V_{\text {test }}$ & $V_{\text {in }} / V_{\text {test }}$ & $V_{\text {out }} / V_{\text {test }}$ & & \\
\hline 1 & $0 \cdot 81$ & $0 \cdot 81$ & - & $0 \cdot 61$ & 1.04 & $1 \cdot 04$ & $0 \cdot 70$ & $0 \cdot 70$ & $1 \cdot 04$ & $0 \cdot 70$ \\
\hline 2 & 1.09 & 1.07 & 0.90 & 0.67 & $1 \cdot 20$ & $0 \cdot 85$ & $1 \cdot 01$ & 0.56 & 0.97 & 0.75 \\
\hline 3 & $1 \cdot 03$ & 0.74 & 0.89 & 0.56 & $1 \cdot 14$ & 0.82 & 0.96 & 0.55 & 0.95 & 0.73 \\
\hline 4 & 0.77 & 0.74 & $0 \cdot 89$ & $0 \cdot 56$ & 0.93 & $0 \cdot 82$ & $0 \cdot 75$ & 0.55 & 0.94 & $0 \cdot 73$ \\
\hline 5 & $1 \cdot 26$ & $1 \cdot 02$ & $0 \cdot 85$ & $0 \cdot 64$ & $1 \cdot 33$ & $0 \cdot 81$ & $1 \cdot 15$ & $0 \cdot 54$ & 0.93 & $0 \cdot 72$ \\
\hline 6 & $1 \cdot 49$ & $1 \cdot 20$ & $1 \cdot 01$ & $0 \cdot 75$ & $1 \cdot 44$ & 0.76 & $1 \cdot 27$ & $0 \cdot 50$ & 0.87 & 0.67 \\
\hline
\end{tabular}

Table 3. Analysis of test results

Note: $* V_{\max }$ calculated with $v_{\mathrm{R}, \mathrm{CS}}=0 \cdot 5 \sqrt{f_{\mathrm{c}}}, \psi$ capacity reduction factor taken as $0 \cdot 75$ from ACI 318 (2005) 
Table 4. Comparison between measured and predicted shear strengths

\begin{tabular}{|c|c|c|c|c|c|c|c|}
\hline \multirow[t]{2}{*}{ Investigator } & \multicolumn{5}{|c|}{ No shear reinforcement } & \multicolumn{2}{|c|}{ Shear reinforcement } \\
\hline & Specimen & $h: \mathrm{mm}$ & $f_{\mathrm{ck}}: \mathrm{MPa}$ & $100 A_{\mathrm{s}} / b d$ & $V_{\text {test }} / V_{\mathrm{c}}$ & $\begin{array}{c}U_{\text {outeff }} / U_{1} \\
\text { (maximum) }\end{array}$ & $\begin{array}{c}V_{\text {test }} / V_{\mathrm{cEC} 2} \\
\text { (maximum) } \gamma_{\mathrm{c}}=1.0\end{array}$ \\
\hline Chana and Desai (1992) & 1 & 240 & 32 & 0.79 & 1.02 & 1.76 & $1.59^{\dagger}$ \\
\hline Regan and Samadian (2001) & 1 & 200 & 40 & $1 \cdot 26$ & $1 \cdot 06$ & 1.44 & $1 \cdot 84$ \\
\hline Regan and Samadian (2001) & $1 \mathrm{a}$ & 200 & 41 & $1 \cdot 26$ & $1 \cdot 02$ & - & - \\
\hline Gomes and Regan (1999) & 1 & 200 & 40 & $1 \cdot 31$ & 1.07 & $1 \cdot 44$ & $2 \cdot 11$ \\
\hline Gomes and Regan (1999) & $1 \mathrm{a}$ & 200 & 41 & $1 \cdot 31$ & $1 \cdot 03$ & $1 \cdot 22 *$ & $1.53 *$ \\
\hline Marzouk and Jiang (1997) & HS17 & 150 & 67 & 1.09 & $0 \cdot 89$ & $1 \cdot 23^{*}$ & $1 \cdot 38^{*}$ \\
\hline Mokhtar et al. (1985) & $\mathrm{AB} 1$ & 250 & 36 & $1 \cdot 33$ & 0.91 & $1 \cdot 23 *$ & $1 \cdot 70^{*}$ \\
\hline Current study & 1 & 220 & 24 & $1 \cdot 28$ & 1.04 & $1 \cdot 11^{*}$ & $1.47 *$ \\
\hline
\end{tabular}

Notes: *ACI shear reinforcement, ${ }^{\dagger}$ failure inside shear reinforcement

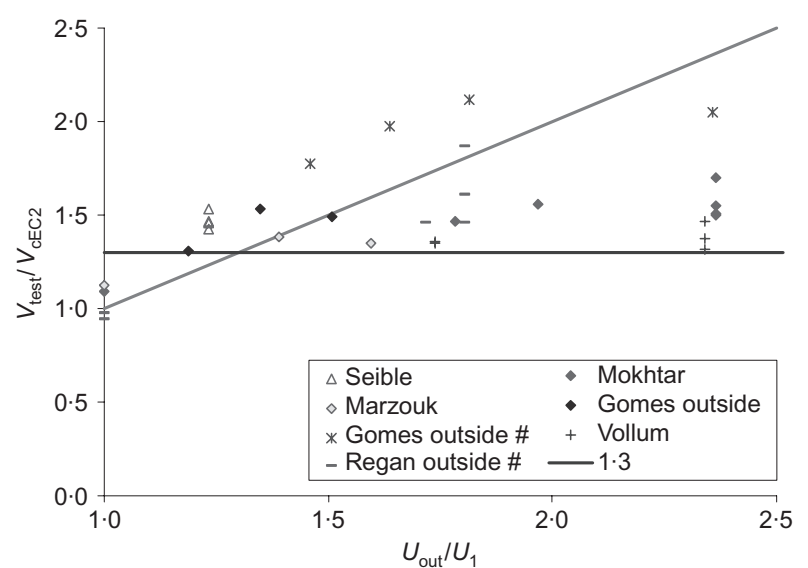

(a)

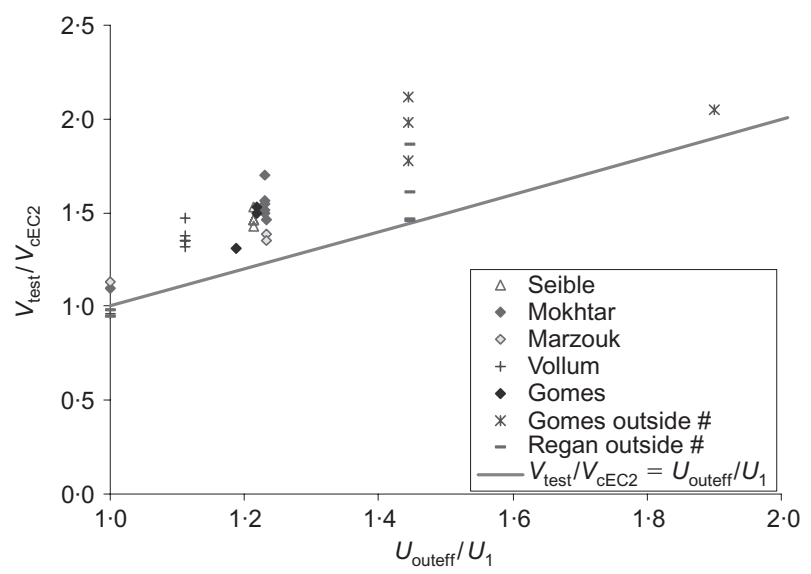

(b)

Figure 6. (a) Influence of $U_{\text {out }}$ on $V_{\text {test }} / V_{c E C 2}$ with $\gamma_{c}=1 \cdot 0$; (b) influence of $U_{\text {outeff }}$ on $V_{\text {test }} / V_{c E C 2}$ with $\gamma_{c}=1 \cdot 0$. Note: \#Radial reinforcement (ACI-type shear reinforcement unless noted otherwise)

outer perimeter $U_{\text {outeff }}$ for ACI-type shear reinforcement is significantly less than the full perimeter $U_{\text {out }}$ shown in Figure 5(b). Figure 6(a) shows that the shear strength of Gomes and Regan's (1999) specimens 6 to 8 , with radial shear reinforcement, which failed outside the shear reinforcement increased almost in proportion with the full outer perimeter $U_{\text {out }}$, despite the maximum circumferential shear reinforcement spacing increasing from $2 \cdot 03 d$ in specimen 6 to $2 \cdot 42 d$ in specimen 7 and $2 \cdot 81 d$ in specimen 8. Of Gomes and Regan's (1999) specimens, only specimen 9 (in which the maximum circumferential stud spacing was $2.67 d$ ) with $U_{\text {out }} /$ $U_{1}=2.36$ falls below the line $V_{\text {test }} / V_{\mathrm{cEC} 2}=U_{\text {out }} / U_{1}$. The reduction in strength of specimen 9 does not appear to have been caused by excessive circumferential stud spacing since the spacing in specimen 9 was less than in specimen 8 which lies above the line $V_{\text {test }} /$ $V_{\mathrm{cEC} 2}=U_{\text {out }} / U_{1}$. The reduction in strength of specimen 9 may be related to Gomes and Regan's (1999) observation that concrete crushing occurred adjacent to the loaded area at failure. The failure load of specimen 9 was also close to the yield line flexural capacity of 1250 kN. Interestingly, Regan and Samadian's (2001) specimens A1, R3 and R4, which had the same geometry as Gomes and Regan's (1999) specimens, and failed outside the shear reinforcement fall below the line $V_{\text {test }} /$ $V_{\mathrm{cEC} 2}=U_{\text {out }} / U_{1}$ in Figure $6(\mathrm{a}) . V_{\text {test }} / V_{\mathrm{cEC} 2}$ calculated with $\gamma_{\mathrm{c}}=1$ is plotted against $U_{\text {outeff }} / U_{1}$ in Figure $6(\mathrm{~b})$, which shows that all the specimens which failed outside the shear reinforcement lie above the line $V_{\text {test }} /$ $V_{\mathrm{cEC} 2}=U_{\text {outeff }} / U_{1}$ as required.

The authors' test results (see Figure 2) suggest that providing stirrups further than $3 d$ from the column face increases ductility but not shear strength for ACI-type shear reinforcement. The influence of stirrups on shear strength is shown in Figure 7 in which $V_{\text {test }} / V_{\mathrm{cEC} 2}$ is plotted against $V_{\mathrm{SEC} 2} / V_{\mathrm{cEC} 2}$ with $\gamma_{\mathrm{c}}=1.0$ and in Figures $8(\mathrm{a})$ to (d) in which $V_{\text {test }} / V_{\mathrm{EC} 2}$ is plotted against $V_{\mathrm{s}} / V_{\mathrm{cEC} 2}$ with $\gamma_{\mathrm{c}}=1.0$ or 1.5 as noted. The contribution of the stirrups $V_{\mathrm{SEC} 2}$ was calculated in Figures 7 and 8 with the design effective strength $f_{\text {ydef }}$ (see Table $2(b)$ ) defined in Eurocode 2 unless noted otherwise. Figure 8(a) shows that the shear strength of all the slabs except some of Chana and Desai's (1992) are safely predicted by Eurocode 2 when $\gamma_{\mathrm{c}}=1 \cdot 0$. It is interesting to note that Eurocode 2 safely predicts the shear strength of Regan and Samadian's (2001) specimens S1 ( $V_{\mathrm{SEC} 2} /$ $\left.V_{\mathrm{cEC} 2}=0.39\right)$ and $\mathrm{S} 2\left(V_{\mathrm{sEC} 2} / V_{\mathrm{cEC} 2}=0.67\right)$, which were reinforced with stirrups similarly to the specimens of 


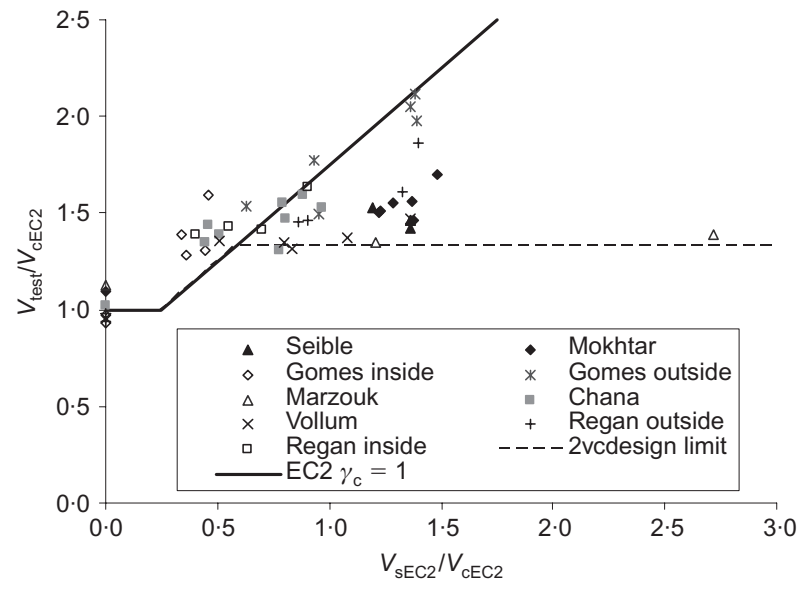

Figure 7. Influence of shear reinforcement on shear strength predicted by Eurocode 2 with $\gamma_{c}=1.0$ and $V_{S E C 2}$ calculated with $f_{\text {ydef }}$

Chana and Desai (1992). The flexural reinforcement ratio $\rho=100 A_{\mathrm{s}} / b d$ was significantly greater in Regan and Samadian's (2001) slabs than in Chana and Desai's (1992) slabs, some of which were close to flexural failure. Regan and Samadian (2001) suggested that the low strength of Chana and Desai's (1992) specimens may have been caused by inadequate anchorage of the stirrups. Figure $8(\mathrm{~b})$ appears to show that Eurocode 2 safely predicts the shear strength of all the specimens when $\gamma_{c}=1.5$ but this is somewhat misleading as discussed below. Figures 8(c) and 8(d) compare measured and predicted shear strengths, calculated with $f_{\text {ydef }}$ and $\gamma_{\mathrm{c}}=1.0$ or 1.5 as noted, for specimens with radial or UK-type shear reinforcement that failed within the shear reinforcement. Figures 8(c) and 8(d) also show shear strengths calculated with $f_{\mathrm{y}}$ (denoted ' $f_{\mathrm{y}}$ ' in Figure 8) for the specimens of Gomes and Regan (1999) in which strain measurements indicate the majority of the I section offsets yielded within the first three perimeters. Figures 8(c) and 8(d) show that the factor of safety implicit in the Eurocode 2 design method for punching shear reduces as $V_{\mathrm{s}}$ increases. Figure $8(\mathrm{c})$ shows that the shear strengths predicted within the shear reinforcement of Gomes and Regan's (1999) specimens 6 to 9 are significantly greater than measured when calculated with $f_{\mathrm{y}}$, which seems most realistic, than with $f_{\text {ydef }}$ as specified in Eurocode 2. In reality, specimens 6 to 9 failed outside the shear reinforcement so the shear capacity within the shear reinforcement is unknown. However, it seems unlikely that it would have been significantly greater than the actual failure load since the majority of the first three rows of shear reinforcement yielded (Gomes and Regan, 1999). This is concerning since (a) $f_{\text {ydef }}$ increases with slab depth to a maximum of $f_{\mathrm{yd}}$ for an effective depth of $750 \mathrm{~mm}$ if

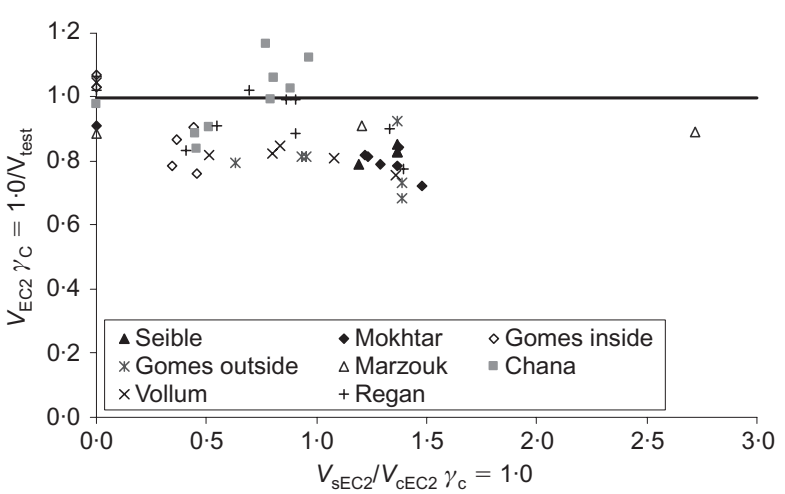

(a)

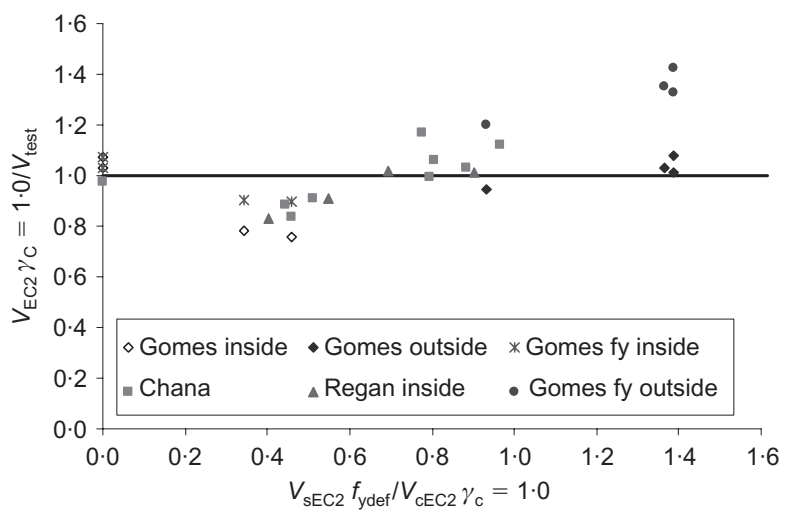

(c)

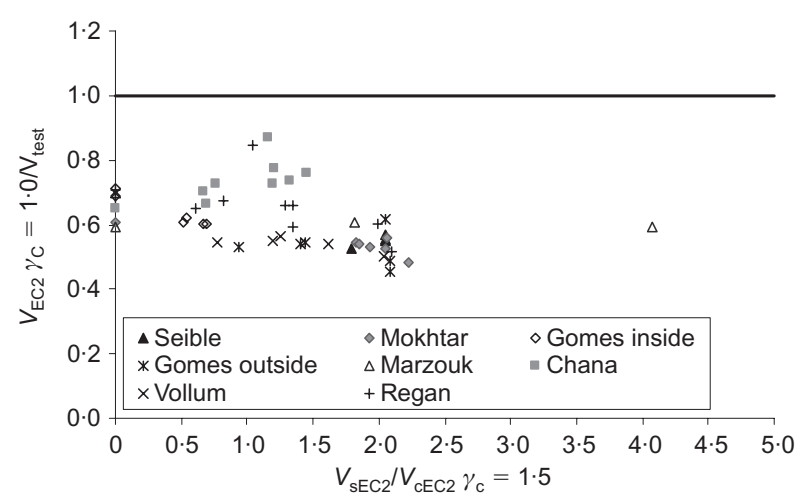

(b)

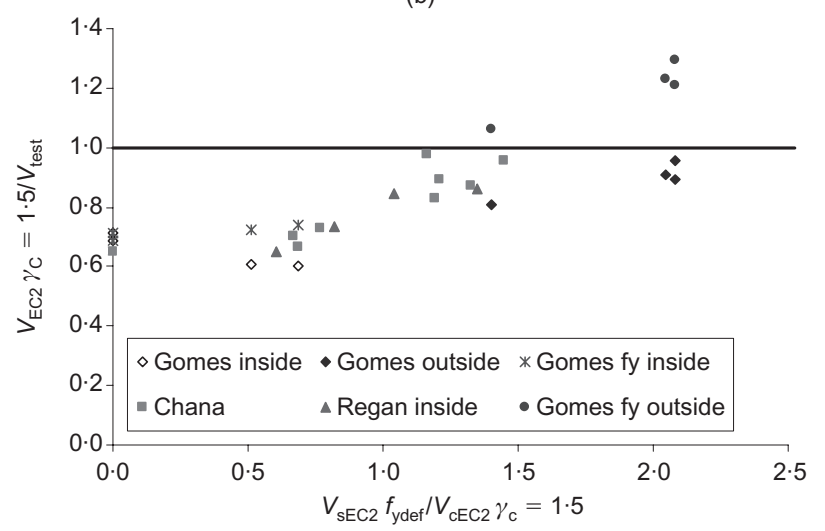

(d)

Figure 8. (a) Influence of stirrups on $V_{\text {test }} / V_{c E C 2}$ : (a) for all slabs with $\gamma_{c}=1.0$ and $f_{\text {ydef }}$; (b) for all slabs with $\gamma_{c}=1.5$ and $f_{\text {ydef }}$; (c) for failure within stirrups with $V_{E C 2}$ calculated with $f_{\text {ydef }}$ unless noted otherwise and $\gamma_{c}=1 \cdot 0$; (d) for failure within stirrups with $V_{E C 2}$ calculated with $f_{\text {ydef }}$ unless noted otherwise and $\gamma_{c}=1 \cdot 5$ 
Table 5. Summary of parametric studies

\begin{tabular}{|c|c|c|c|c|c|c|c|c|}
\hline \multirow[t]{2}{*}{ Parametric study } & \multirow[t]{2}{*}{$f_{\mathrm{c}}: \mathrm{MPa}$} & \multirow[t]{2}{*}{$\rho: \%$} & \multicolumn{3}{|c|}{ Description of shear reinforcement } & \multicolumn{3}{|c|}{ Failure load: $\mathrm{kN}$} \\
\hline & & & $\begin{array}{c}\text { Diameter and spacing of } \\
\text { stirrups }\end{array}$ & $\alpha$ & $\begin{array}{l}\text { Stirrup width } x: \\
\text { mm }\end{array}$ & NLFEA & $\begin{array}{c}\text { Eurocode } 2 \\
\gamma_{\mathrm{c}}=1 \cdot 0\end{array}$ & $\begin{array}{l}\text { Proposed } \\
\gamma_{\mathrm{c}}=1 \cdot 0\end{array}$ \\
\hline $\mathrm{P} 1$ & 24 & $1 \cdot 28$ & 6 mm@90mm & 5 & 150 & 876 & 713 & 850 \\
\hline $\mathrm{P} 2$ & 24 & $1 \cdot 28$ & 10 mm@180mm & 5 & 150 & 880 & 713 & 850 \\
\hline P3 & 24 & $1 \cdot 28$ & 10 mm@90mm & 5 & 270 & 876 & 807 & 855 \\
\hline
\end{tabular}

$f_{\text {yd }}=435 \mathrm{MPa}$ and (b) the majority of punching tests have been carried out on relatively thin slabs where $f_{\text {ydef }}$ is significantly less than $f_{\text {yd }}$. Comparison of Figures $8(\mathrm{c})$ and $8(\mathrm{~d})$ shows that the reduction in the overall factor of safety with increasing $V_{\mathrm{s}} / V_{\mathrm{c}}$ is more pronounced when $\gamma_{c}=1 \cdot 5$. The reason for this can be seen when Equation T2 in Table 2(a) is expressed in the form

$$
\begin{aligned}
V_{\mathrm{Rd}} & =V_{\text {test }} / \mathrm{FOS}=\left(0.75 V_{\mathrm{cEC} 2}+V_{\mathrm{sEC} 2}\right) / \mathrm{FOS} \\
& =0.75 V_{\mathrm{cdEC} 2}+V_{\mathrm{sdEC} 2}
\end{aligned}
$$

where $V_{\mathrm{Rd}}$ is the design shear strength, 1/FOS is the multiple by which the shear strength calculated with Eurocode 2 is reduced when $\gamma_{c}$ is increased from 1 to 1.5 if shear failure occurs within the shear reinforcement, $V_{\text {test }}$ is the measured shear strength and $V_{\mathrm{SEC} 2}$ is the contribution of the shear reinforcement which is calculated in Eurocode 2 with the least of $f_{\text {ydef }}$ or $f_{\mathrm{y}} / \gamma_{\mathrm{s}}$. When $f_{\mathrm{ydef}}$ is less than $f_{\mathrm{yd}}, V_{\mathrm{sEC} 2}=V_{\mathrm{sdEC} 2}$ in which case, rearranging Equation 6 gives

$$
\mathrm{FOS}=1+\frac{0 \cdot 75 V_{\mathrm{cdEC} 2}\left(\gamma_{\mathrm{c}}-1\right)}{V_{\mathrm{Rd}}}
$$

where FOS is the ratio between the calculated shear strengths in Figures 8(c) (with $\gamma_{\mathrm{c}}=1 \cdot 0$ ) and 8(d) (with $\left.\gamma_{\mathrm{c}}=1 \cdot 5\right)$, for $V_{\mathrm{Rd}}>V_{\mathrm{cdEC} 2}$, which reduces as the design shear resistance $V_{\mathrm{Rd}}$ increases.

The design strength of some specimens in Figure 8(d) is reduced in Figure 8(b) as failure is incorrectly predicted to occur outside the shear reinforcement when $\gamma_{\mathrm{c}}$ is increased to 1.5. It follows that Figure 8(b) gives a misleading picture of the overall factor of safety implicit in Eurocode 2 for punching shear since the code requires sufficient perimeters of shear reinforcement to be provided to ensure failure occurs within the shear reinforced zone. It follows that Figure 8(d), which shows predicted punching strengths within the shear reinforcement, gives the most realistic indication of the factor of safety likely to occur in practice excluding any benefit from compressive membrane action. Figure 8(d) suggests that the Eurocode 2 design method for punching shear reinforcement is only satisfactory for design shear strengths up to around $2 V_{\text {cd. }}$.

The design shear strength of specimens with ACItype shear reinforcement is reduced disproportionately compared with other types of shear reinforcement when $\gamma_{c}$ is increased to 1.5 as the length of the outer perimeter $U_{\text {outeff }}$ is fixed once the distance $\alpha d$ to the outer perimeter of shear reinforcement reaches a limiting value. Table 4 shows the maximum possible increases in shear strength $U_{\text {outeffmax }} / U_{1}$ allowed by Eurocode 2 are less than observed. Table 3 suggests that Eurocode 2 , with $\gamma_{c}=1 \cdot 5$, is unnecessarily conservative for ACItype shear reinforcement if the shear failure is within the shear reinforcement (i.e. the authors' test 4) or if the stirrups extend sufficiently far from the column to ensure a ductile failure as observed in the authors' tests 2, 5 and 6 where the last stirrup was placed $5 d$ from the face of the loaded area.

\section{Numerical investigation}

This section describes a series of three-dimensional (3D) finite-element analyses which were carried out with DIANA v9.3 to gain an insight into the failure mechanism of the tested specimens with a view to developing an improved design method. A total-strain constitutive model was used for the concrete (Vecchio and Collins, 1993), which is capable of modelling the effects of concrete cracking, crushing confinement and softening. The stress-strain curve for concrete under uniaxial stress is shown in Figure 9.

\section{Finite-element model}

Figures $10(\mathrm{a})$ to $10(\mathrm{c})$ show the $3 \mathrm{D}$ finite-element mesh used to model one quarter of the slab. The

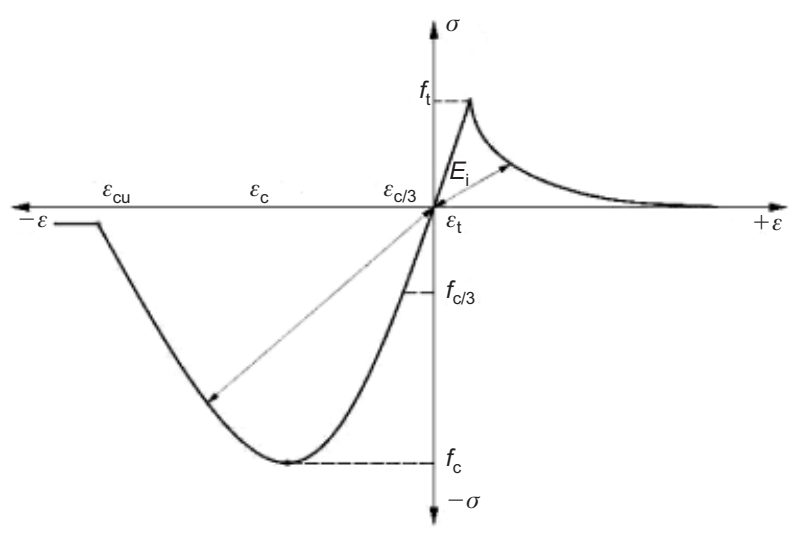

Figure 9. Stress-strain diagram for concrete 


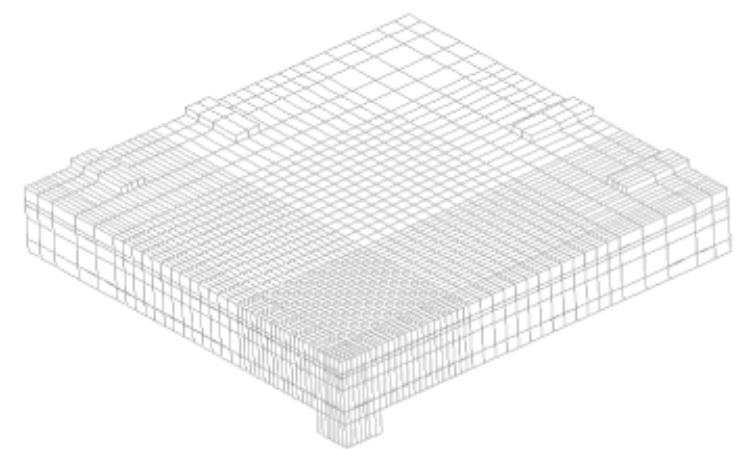

(a)

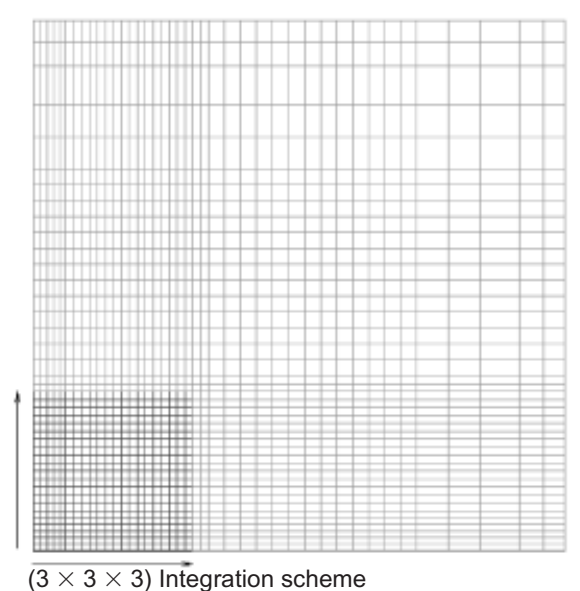

(b)

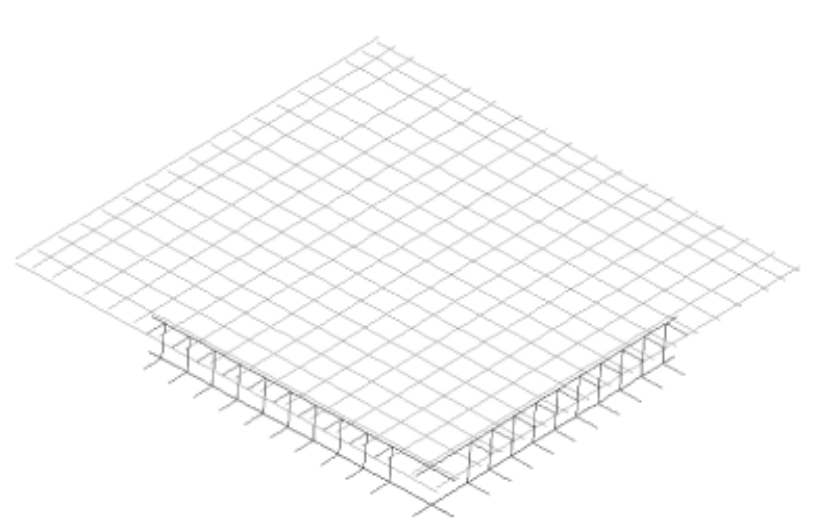

(c)

Figure 10. Finite-element mesh (a) 3D view; (b) plan view; (c) reinforcement arrangement

concrete slab and steel bearing plates were modelled with 20-noded brick elements, and the reinforcement was modelled with compatible 3-noded truss elements. The interface between the steel loading plates and the concrete slab was modelled with 16 -node ( 8 nodes at each side of the interface) surface interface elements. Modelling the reinforcement with discrete rather than embedded elements highly constrains the mesh topology. The gradated mesh shown in Figure 10(b) was used to reduce the size of the problem. The slab was divided into five layers of elements through its thick- ness. A full integration scheme $(3 \times 3 \times 3)$ was assigned to the solid elements in the slab adjacent to the loaded area as shown in Figure 10(b). A reduced integration scheme $(2 \times 2 \times 2)$ was used for the remainder of the solid elements. Full bond was assumed between the concrete and the reinforcement throughout this study. The number of nodes in the model was 40708 .

\section{Material modelling}

The concrete was modelled with the 'total strain model' in Diana, which is based on the models of Vecchio and Collins (1993) and Selby and Vecchio (1993). A fixed crack variant of the model was used in the current analysis in which the stress-strain relationships are evaluated in the directions of the principal axes at first cracking. Stresses are calculated in terms of total strains. A secant approach was used for unloading in which the stress-strain relationship unloads linearly to the origin before switching between the tension and compression loading curves as appropriate. The stress-strain response of the concrete in tension is assumed to be linear until cracking. After cracking, the tensile stress was assumed to reduce exponentially with strain in the crack normal direction $n n$ as follows (see Figure 9)

$$
\sigma_{\mathrm{nn}}^{\mathrm{cr}}\left(\varepsilon_{\mathrm{nn}}^{\mathrm{cr}}\right)=f_{\mathrm{t}} \exp \left(-\frac{\varepsilon_{\mathrm{nn}}^{\mathrm{cr}}}{\varepsilon_{\mathrm{nn}, \mathrm{ult}}^{\mathrm{cr}}}\right)
$$

where $f_{\mathrm{t}}$ is the uniaxial tensile strength; $\varepsilon_{\mathrm{nn}, \mathrm{ult}}^{\mathrm{cr}}$ is the ultimate crack strain normal to the crack which is defined in terms of the fracture energy $G_{\mathrm{f}}$ for tensile failure and the crack band width, $h$, as follows

$$
\varepsilon_{\mathrm{nn}, \mathrm{ult}}^{\mathrm{cr}}=\frac{G_{\mathrm{f}}}{h f_{\mathrm{t}}}
$$

The fracture energy for tensile crack propagation was calculated in accordance with the recommendations of CEB-FIP model code 1990 (CEB-FIP, 1993) as follows

$$
G_{\mathrm{f}}=G_{\mathrm{f} 0}\left(\frac{f_{\mathrm{c}}}{f_{\mathrm{c} 0}}\right)^{0 \cdot 7}
$$

where $G_{\mathrm{f} 0}$ is base value of fracture energy. $G_{\mathrm{f} 0}$ depends on the maximum aggregate size $d_{\max }$ and is given in table format in the code. $G_{\mathrm{fo}}$ was taken as $0.035 \mathrm{Nmm} /$ $\mathrm{mm}^{2}$ in the current analysis since the maximum aggregate size was $20 \mathrm{~mm} . f_{\mathrm{c} 0}=10 \mathrm{MPa}$.

The crack band width was assigned the default value of $\sqrt[3]{V}$ where $V$ is the volume of the element. The compressive behaviour is described by a parabolic hardening and softening law suggested by Feenstra (1993). The parabolic curve is defined in terms of the three strains shown in Figure 9. The strain $\varepsilon_{\mathrm{c} / 3}$ at which the compressive stress equals $1 / 3$ of the compressive strength $f_{\mathrm{c}}$ is given by

Magazine of Concrete Research, 2010, 62, No. 1 


$$
\varepsilon_{\mathrm{c} / 3}=-\frac{1}{3} \frac{f_{\mathrm{c}}}{E_{\mathrm{c}}}
$$

The strain $\varepsilon_{\mathrm{c}}$ at which the compressive stress equals the compressive strength is given by

$$
\varepsilon_{\mathrm{c}}=-\frac{5}{3} \frac{f_{\mathrm{c}}}{E_{\mathrm{c}}}
$$

where $\varepsilon_{\mathrm{c}}$ was assumed to be -0.003 in the current study. The ultimate strain $\varepsilon_{\mathrm{cu}}$, at which the concrete completely softens in compression, is given by

$$
\varepsilon_{\mathrm{cu}}=\varepsilon_{\mathrm{c}}-\frac{3}{2} \frac{G_{\mathrm{c}}}{h f_{\mathrm{c}}}
$$

where $h$ is the crack bandwidth and $G_{\mathrm{c}}$ is specific fracture energy for compressive failure.

The increase in concrete compressive strength with isotropic stress was modelled with the four-parameter Hsieh-Ting-Chen (Chen 1982) failure surface. The reduction in compressive strength owing to lateral cracking was modelled in accordance with the recommendations of Vecchio and Collins (1993). A constant shear retention factor $\beta$ was used after cracking (i.e. the secant modulus for shear after cracking, $G^{\text {cr }}=\beta G$ with $0 \leqslant \beta \leqslant 1$ ).

\section{Estimation of material parameters}

The concrete material properties used in the analysis were derived from a series of parametric studies of slabs failing in punching without shear reinforcement. A sensitivity analysis was carried out to determine the sensitivity of the failure load and displacements to variations in $f_{\mathrm{t}}, \beta$ and $G_{\mathrm{c}}$. The study showed that the concrete tensile strength $f_{\mathrm{t}}$ has the greatest influence on the predicted response. Good comparisons were obtained between the measured and predicted responses when the concrete tensile strength was calculated with Equation 14 below from ACI 209 model code (ACI, 1982)

$$
f_{\mathrm{t}}=0.0069 \sqrt{w f_{\mathrm{c}}} \quad \mathrm{MPa}
$$

where $w$ is the concrete density in $\mathrm{kg} / \mathrm{m}^{3}$. The concrete cube strength was used in Equation 14 instead of the cylinder strength specified in ACI 209. Equation 14 gives $f_{\mathrm{t}}=1.85 \mathrm{MPa}$ for $w=2400 \mathrm{~kg} / \mathrm{m}^{3}$ and $f_{\mathrm{c}}=$ $30 \mathrm{MPa}$ (cube strength), which is low compared with the tensile strengths derived from splitting tests in the laboratory. Recently, Lee et al. (2008) carried out a series of direct tension tests on large-scale normalweight concrete specimens (specimen size $=1400 \mathrm{~mm}$ long $\times 1100 \mathrm{~mm}$ wide $\times 250 \mathrm{~mm}$ thick) in which they found that the direct tensile strength was about half the indirect tensile strength of cylindrical specimens. The direct tensile strengths $f_{\mathrm{t}}(\mathrm{MPa})$ measured in Lee et al.'s (2008) tests ranged from $f_{\mathrm{t}}=0 \cdot 27 \sqrt{f_{\mathrm{ck}}}$ to $f_{\mathrm{t}}=0 \cdot 37 \sqrt{f_{\mathrm{ck}}}$ with a mean of $f_{\mathrm{t}}=0 \cdot 30 \sqrt{f_{\mathrm{ck}}}$. The corresponding values of $f_{\mathrm{t}}$ range between $1.33 \mathrm{MPa}$ to
$1.83 \mathrm{MPa}$ for $f_{\text {ck }}=24 \mathrm{MPa}$, which is comparable to the value of $1.85 \mathrm{MPa}$ given by Equation 14, which was used to derive the tensile strengths employed in the current analyses.

A value of 0.2 was adopted for the shear retention factor $\beta$, which was found to influence the failure load significantly but not the deflection. The shear retention factor was locally increased to $0 \cdot 3$ in the thin layer of elements around the tension reinforcement indirectly to model the influence of dowel action. The parametric studies showed that the compressive fracture energy $G_{\mathrm{c}}$ had no significant influence on the predicted response of the slabs. $G_{\mathrm{c}}$ was taken as $10 \mathrm{Nmm} / \mathrm{mm}^{2}$ in all analyses reported in this paper. Poisson's ratio was taken as 0.15 for concrete. The reinforcement was modelled as perfectly elasto-plastic using von Mises formulation. The elastic modulus of the reinforcement was taken as $200 \mathrm{GPa}$. The steel bearing plates and loading platen were modelled elastically. The interface between the steel loading platen and the concrete was modelled with interface elements, which had a very high compressive stiffness $(210 \mathrm{MPa} / \mathrm{m})$ and negligible tensile stiffness.

\section{Finite-element analysis}

The slabs were loaded in two phases. The slab selfweight was activated in the first phase of the analysis in which the slab was supported on the central loading platen. The elements representing the steel bearing plates at the edge of the slab were activated in the second phase of the analysis along with the corresponding vertical restraints. The vertical displacement was assumed to be zero at the centre of the bearing plates whereas in reality the rig was designed to ensure that the vertical reactions were equally distributed between the 16 restraining tie bars placed around the perimeter of the slab. Displacement-controlled loading was used with an iterative-based loading technique in which the initial loading step was taken as $0.15 \mathrm{~mm}$ with a maximum step size of $0.2 \mathrm{~mm}$. The actual size of any loading step is calculated by the programme and depends on the number of iterations required for convergence in the previous load step compared with an optimum number of iterations which was set at 6. A quasi-Newton (secant) iteration method was used as an iteration process for the loading steps. An energy-based convergence criterion was used with a tolerance value of $1 \times 10^{-3}$.

\section{Numerical results}

The measured and predicted load against central displacement responses of slabs 1 to 6 are compared in Figures 11(a) to 11(b). The figures show good agreement between (a) the measured and predicted initial stiffness, (b) the loads at which the stiffness reduces owing to cracking and (c) the ultimate load. The measured and predicted failure loads are also compared in Table 1. The difference between the measured and 


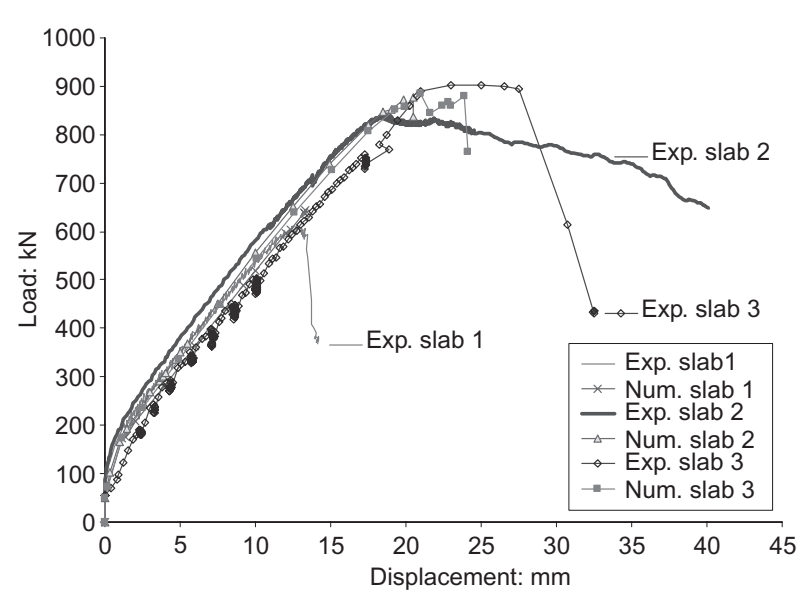

(a)

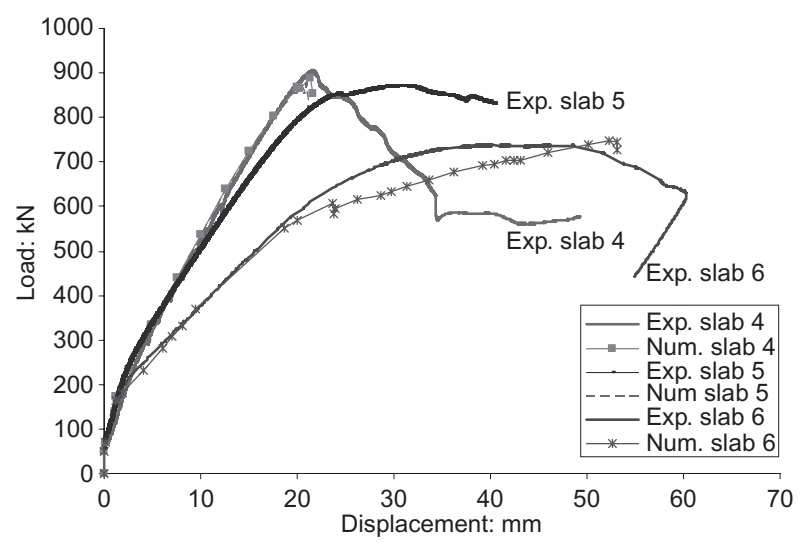

(b)

Figure 11. Comparison between measured and predicted response: (a) for slabs 1 to 3; (b) for slabs 4 to 6

predicted failure loads did not exceed 5\%, which is an excellent result given that the material parameters used in the analysis were chosen in the light of a series of parametric studies on slabs without shear reinforcement. The analysis did not realistically simulate the post-peak behaviour of the slabs. The smeared crack approach is unable fully to simulate punching shear failures since it results in a much more extensive distribution of cracks than occurs in reality. The punching shear failure is represented in Figure 11, which shows incremental displacements at the final load step. Figure 12 shows a step in the vertical displacements in the top surface of the slab at around $700 \mathrm{~mm}$ from the slab centre line which is consistent with the behaviour observed in test 6 where the punching failure was visible in the top surface of the slab at around $900 \mathrm{~mm}$ from the slab centreline. The analysis did not model the debonding of the flexural reinforcement which was observed when the slabs were sawn in half. The analysis

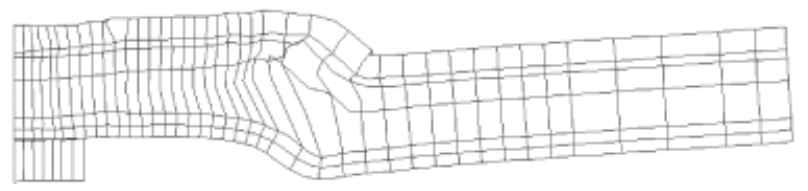

Figure 12. Deformed shape at ultimate load level predicted that the flexural reinforcement yielded at the column face in all the tests and that the zone of yielding extended to the perimeter of the failure surface. The stirrups were not predicted to yield at failure.

\section{Parametric study}

A series of parametric studies were carried out to investigate the effect of varying

(a) the area of and spacing of the shear reinforcement (b) the width of the stirrups.

The results of the parametric studies are summarised in Table 5, which also gives the shear strengths predicted with Eurocode 2. Both the non-linear finite-element analysis (NLFEA) and Eurocode 2 predicted the shear strength of the specimens analysed to be independent of the area of shear reinforcement provided. The NLFEA, unlike Eurocode 2, predicted the shear strength to be unchanged when the width of the stirrups was increased from $150 \mathrm{~mm}$ (as in the authors' tests) to the width of the loading platen (i.e. $270 \mathrm{~mm}$ ). Unfortunately, there are insufficient test data to determine which of these predictions is most realistic.

\section{Proposed design method}

Back-analysis of the test data considered in this paper suggests that the effective outer shear perimeter can be calculated as follows for ACI-type shear reinforcement

$$
U_{\text {outeff }}=4(x+\pi d+2 d)
$$

Figure 13 shows the control perimeter corresponding to Equation 15. Equation 7 gives the multiple by which the shear strength calculated with Eurocode 2 increases when $\gamma_{\mathrm{c}}$ is reduced from 1.5 to 1.0 if shear failure occurs within the shear reinforcement. This multiple reduces from 1.25 when $V_{\mathrm{Rd}} / V_{\mathrm{cdEC} 2}=1.5$ (in which case $V_{\mathrm{Rd}}=V_{\mathrm{cEC} 2}$ calculated with $\left.\gamma_{\mathrm{c}}=1.0\right)$ to 1.125 when $V_{\mathrm{Rd}} / V_{\mathrm{cdEC} 2}=3 \cdot 0$. This multiple is not equal to the true factor of safety which is shown in Figure 8(c) to reduce from around 1.5 for $V_{\mathrm{sEC} 2}=0\left(V_{\mathrm{Rd}} / V_{\mathrm{cdEC} 2}=\right.$ $1 \cdot 0)$ to in some cases less than 1 for $V_{\mathrm{sEC} 2} / V_{\mathrm{cEC} 2}=0.77$

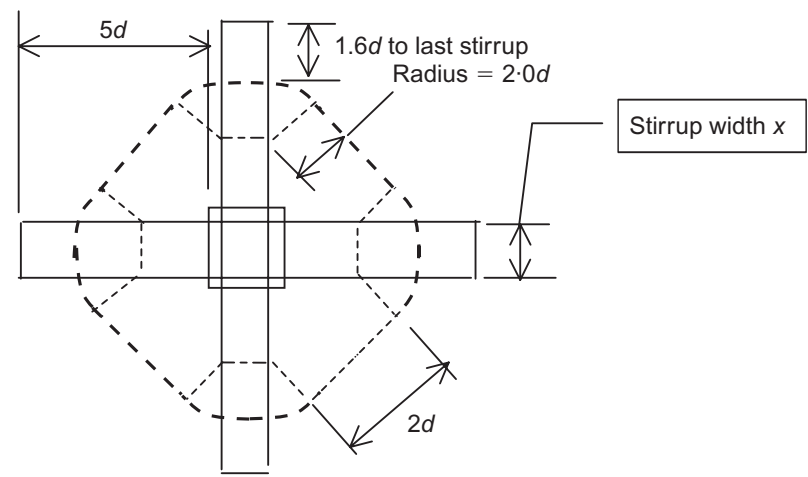

Figure 13. Proposed outer perimeter

Magazine of Concrete Research, 2010, 62, No. 1 
$\left(V_{\mathrm{Rd}} / V_{\mathrm{cdEC} 2} \geqslant 2 \cdot 3\right)$. Figure $8(\mathrm{~d})$ suggests that the level of safety provided by the Eurocode 2 design method for shear reinforcement is reasonable for design shear forces up to around $2 V_{\mathrm{cd}}\left(\right.$ or $\left.V_{\mathrm{sEC} 2} / V_{\mathrm{cd}}=1 \cdot 25\right)$. Figure 7 shows that the maximum shear strength achievable with ACI-type shear reinforcement is around $2 \cdot 0 V_{\mathrm{cdEC} 2}$, which corresponds to a design shear strength of $V_{\mathrm{Rd}}=2 \cdot 0 V_{\mathrm{cdEC} 2} / \mathrm{FOS}=1 \cdot 6 V_{\mathrm{cd}}$ when FOS is calculated with Equation 7 . It follows that the maximum design shear resistance should be limited to

$$
\begin{aligned}
V_{\text {design }} \leqslant & V_{\text {Rdcs }} \leqslant V_{\max }=4\left(\frac{\gamma_{\mathrm{c}}}{\mathrm{FOS}}\right) \\
& \times(x+\pi d+2 d) d v_{\mathrm{cdEC} 2} \leqslant 1.6 \mathrm{~V}_{\mathrm{cdEC} 2}
\end{aligned}
$$

where $V_{\text {Rdcs }}$ is the shear resistance calculated with Equation T2 (see Table 2(a)) and

$$
\left(\frac{\gamma_{\mathrm{c}}}{\mathrm{FOS}}\right)=\frac{\gamma_{\mathrm{c}} U_{\text {outeff }}}{U_{\text {outeff }}+0.75 U_{1}\left(\gamma_{\mathrm{c}}-1\right)}
$$

Equation 16 was used to calculate the shear strengths of the specimens in the authors' database with ACI-type shear reinforcement. The results are shown in Figure 14(a) (with $\gamma_{\mathrm{c}}=1.0$ and $f_{\text {ydef }}$ ) and in Figure $14(\mathrm{~b})$ (with $\gamma_{\mathrm{c}}=1.5$ and $f_{\mathrm{y}}$ limited to $300 \mathrm{MPa}$ for reasons discussed below). The shear strength of the specimens with ACItype shear reinforcement in Figure 14 was typically

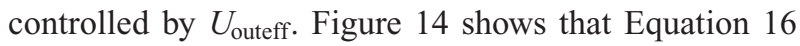
gives comparable overall factors of safety for specimens with ACI-type shear reinforcement to those obtained with Eurocode 2 for the tests of Gomes and Regan (1999) and Regan and Samadian (2001) with radial or UK-type arrangements of shear reinforcement.

\section{Conclusions}

Process research at Cardington (Goodchild 2000) showed ACI-type shear reinforcement to be very costeffective since it is relatively quick to install. The current research shows that ACI-type shear reinforcement can increase the shear strength of specimens without shear reinforcement by multiples of up to 1.5 , which is frequently sufficient in practice, compared with multiples of $2 \cdot 0$ or more for well-anchored radial shear reinforcement. Eurocode 2 gives very conservative maximum possible design shear strengths for slabs reinforced with ACI-type shear reinforcement since the the length of the outer shear perimeter $U_{\text {outeff }}$ is capped. This paper proposes an amendment to Eurocode 2 which gives comparable factors of safety for ACI-type shear reinforcement to other types of shear reinforcement when failure is within the shear reinforcement. The FOS in Equation 16 should be taken as 1.5 unless the shear reinforcement is extended $5 d$ from the column face as shown in Figure 12 to increase the ductility of the punching failure. Equation 7 shows that the multiple FOS by which the shear strength calculated

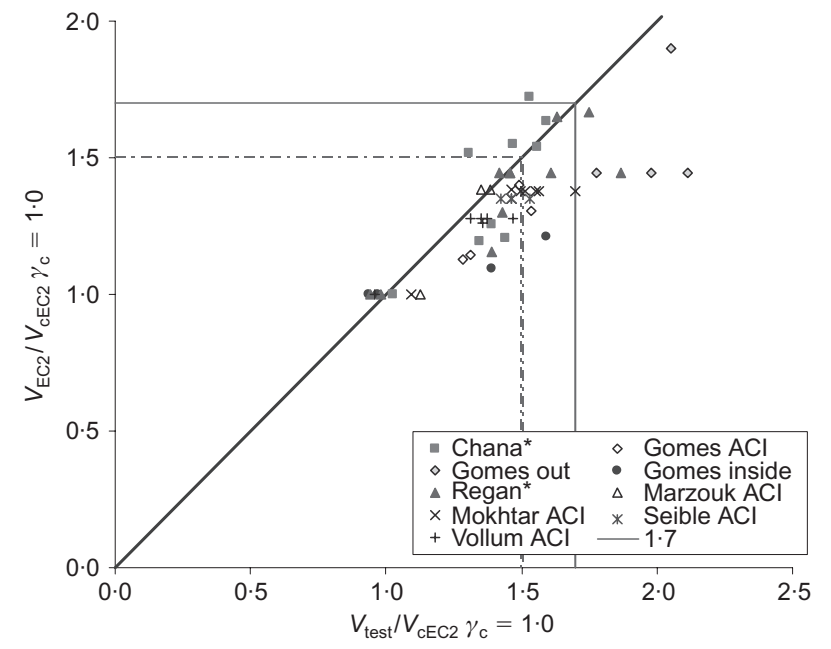

(a)

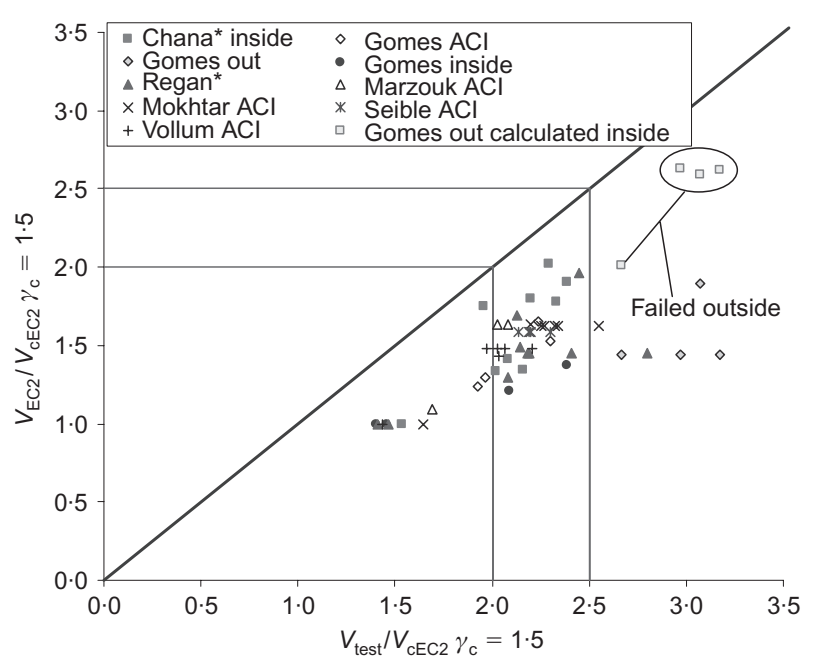

(b)

Figure 14. Accuracy of proposed method for designing ACI shear reinforcement: (a) $V_{E C 2}$ calculated with $\gamma_{c}=1.0$ and $f_{\text {ydef; }}$; (b) $V_{E C 2}$ calculated with $\gamma_{c}=1.5$ and $f_{y d}<300 /$ $1.15 \mathrm{MPa}$

with Eurocode 2 increases when $\gamma_{c}$ is reduced from 1.5 to 1.0 reduces with increasing design shear force. This reduction in safety factor is questionable as Eurocode 2 is shown progressively to overestimate the contribution of punching shear reinforcement to shear strength with increasing design shear force. For example, Figures 8(b), 8(c) and 14(a) show that Eurocode 2 tends to overestimate the strength of Chana and Desai's (1992) specimens with $V_{\mathrm{Rd}} / V_{\mathrm{cd}}>2$ if the design shear strength is controlled by the stirrups as observed. The shear strength of some of Gomes and Regan's (1999) specimens may also be overestimated within the shear reinforcement if calculated with $f_{y}$, which seems most realistic since the shear reinforcement yielded in the tests. This makes the increase in $f_{\text {ydef }}$ with slab depth in Eurocode 2 questionable since the majority of punching shear tests have been carried out on relatively thin slabs where $f_{\text {ydef }}$ is significantly less than $f_{\text {yd }}$. Furthermore, 
the degree of conservatism in $f_{\text {ydef }}$ is uncertain since strains are seldom measured in the shear reinforcement. It follows that the contribution of the shear reinforcement should be reduced in Eurocode 2 to give safe design shear strengths with $f_{\text {yd }}$ for specimens such as those of Gomes and Regan (1999) in which the shear reinforcement is known to have yielded. Figure 14(b) suggests that a quick fix to Equation $\mathrm{T} 2$ is to limit $f_{\mathrm{y}}$ to $300 \mathrm{MPa}$ and the maximum possible design shear force $V_{\mathrm{ED}}$ to $2 \cdot 5 V_{\text {cd. }}$ In the future, the stirrup contribution should be related to the design shear stress (alternatively the concrete contribution could be reduced with increasing $V_{\mathrm{ED}}$ ), the type of shear reinforcement and its anchorage rather than solely the effective depth of the slab.

\section{References}

ACI (American Concrete Institute) (2005) Building Code Requirements for Reinforced Concrete. ACI, Detroit, ACI Committee 318, ACI 318-2005

ACI (American Concrete Institute) (1982) Prediction of Creep, Shrinkage, and Temperature Effects in Concrete Structures. ACI, Detroit, ACI Committee 209, Technical report ACI 209R-82.

BSI (British Standards Institution) (2007) Structural Use of Concrete. BSI, London, BS 8110-1: 1997

BSI (British Standards Institution) (2004) Eurocode 2: Design of Concrete Structures. Part 1: General Rules and Rules for Buildings. BSI, London, 2004, BS EN 1992-1-1.

CEB-FIP (Comité Euro-International du Béton-Fédération Internationale de la Précontrainte) (1993) CEB-FIP model code 1990. CEB, Paris.

Chana PS and Desai SB (1992) Design of shear reinforcement against punching. Structural Engineer 1992, 70(9): 159-164.
Chen WF (1982) Plasticity in reinforced concrete. McGraw-Hill, New York.

Feenstra PH (1993) Computational aspects of biaxial stress in plain and reinforced concrete. $\mathrm{PhD}$ thesis, Delft University of Technology.

Gomes R and Regan P (1999) Punching strength of slabs reinforced for shear with offcuts of rolled steel I-section beams. Magazine of Concrete Research 51(2): 121-129.

Goodchild CH (2000) Rationalisation of flat slab reinforcement. British Cement Publication 97: 376.

Hawkins N, Bao A and Yamazaki J (1989) Moment transfer from concrete slabs to columns. ACI Structural Journal 86(6): 705-716.

Lee S-K, Woo S-K and Song Y-C (2008) Softening response properties of plain concrete by large-scale direct tension tests. Magazine of Concrete Research 60(1): 33-40.

Marzouk H and Jiang D (1997) Experimental investigation on shear enhancement types for high-strength concrete plates. ACI Journal 94(1): 49-58.

Mokhtar A-S, Ghali A and Dilger W (1985) Stud shear reinforcement for flat concrete plates. ACI Journal 82(5): 676-683.

Regan PE and Samadian F (2001) Shear reinforcement against punching in reinforced concrete flat slabs. The Structural Engineer 79(10): 24-31.

Seible F, Ghali A and Dilger W (1980) Preassembled shear reinforcing units for flat slabs. ACI Journal 77(1): 28-35.

Selby RG and Vecchio FJ (1993) Three-dimensional constitutive relations for reinforced concrete. University of Toronto, Canada, Technical report 93-02.

Vecchio FJ and Collins MP (1993) Compression response of cracked reinforced concrete. Journal of Structural Engineering, ASCE 119(12): 3590-3610.

Walraven JC (2001) Punching shear. Background document for prENV 1992-1-1:2001. Comité Européen de Normalisation, Brussels.

Discussion contributions on this paper should reach the editor by 1 July 2010 